\title{
Study of specific discharge energy in WEDM and its application
}

\author{
Y.S. Liao ${ }^{\mathrm{a}, *}$, Y.P. $\mathrm{Yu}^{\mathrm{b}}$ \\ a Department of Mechanical Engineering, National Taiwan University 1, Sec. 4, Roosevelt Road, Taipei 106, Taiwan \\ b Department of Mechanical Engineering, Hwa-Hsia College of Technology and Commerce, No. 111, Huashin Street, Junghe City, \\ Taipei 235, Taiwan
}

Received 30 September 2003; received in revised form 7 April 2004; accepted 22 April 2004

\begin{abstract}
The relationship between machining parameters and machining characteristics of different materials in WEDM is difficult to obtain because a large number of experiments must be conducted repeatedly. A new concept attempting to solve this problem is presented in this paper. The specific discharge energy (SDE) defining as the real energy required to remove a unit volume of material is proposed. The SDE is constant for a specific material. Experimental results reveal that the relative relationship of SDE between different materials is invariant as long as all materials are machined under the same machining conditions. It is also found that the materials having close value of SDE demonstrate very similar machining characteristics such as machining speed, discharge frequency, groove width and surface finish of the machined surface under the same machining conditions. This result can be applied for the determination of the settings of machining parameters of different materials. Furthermore, by dimensional analysis of SDE, a quantitative relationship between machining characteristics such as the material removal rate and the efficiency of material removal and machining parameters is derived.
\end{abstract}

(C) 2003 Elsevier Ltd. All rights reserved.

Keywords: Wire electrical discharge machining; Process planning; Specific discharge energy; Discharge efficiency

\section{Introduction}

Different materials have different characteristics, including machining speed, surface roughness of the machined surface, groove width, discharge frequency, abnormal discharge ratio, under different machining conditions in WEDM. Different materials even when they are machined under the same machining conditions exhibit different machining characteristics. It is difficult to control and predict the machining characteristics in WEDM. There are very few studies on this subject so far. Almost all the studies concerned with material deal with the effect of electrode material on machinability in WEDM or die sinking EDM [1,2]. Levy and Maggi [3] have compared the influence of material properties of different steels on machining characteristics, but only qualitatively. The material

\footnotetext{
${ }^{*}$ Corresponding author. Tel.: +886-2-2362-6431; fax: +886-2-23631755.

E-mail address: liaoys@ntu.edu.tw (Y.S. Liao).
}

properties such as melting point, density, specific heat, thermal conductivity, yield strength, etc., all should affect machining characteristics. It is extremely difficult to conclude and pinpoint a concise and definite physical quantity that can fully reflect the material properties in WEDM, and use it to predict machining characteristics. In general, the material removal rate and machining characteristics during the WEDM process depend on the distribution of the energy supplied to the gap by the electrical current. Various thermal models proposed for EDM [4-7] show that the complexities and the stochastic nature of multiple discharges render difficulties in analyzing the process theoretically. From the energy point of view, a quantity defining as the real energy required to remove a unit volume of a specific material in wire electrical discharge machining and coined (SDE) is proposed in the paper. The SDE should be constant for a given material, and it is considered as one of the material properties in WEDM. The SDEs of different materials are compared first in the paper. Materials having close values of SDE 


\begin{tabular}{|ll|}
\hline Nomenclature \\
$A_{\text {on }}$ & arc on time \\
$A_{\text {off }}$ & arc off time \\
$c$ & specific heat \\
$D$ & erosion diameter of single discharge \\
$\Delta E$ & single discharge energy \\
$F$ & table feed rate \\
$F_{\mathrm{w}}$ & flushing pressure \\
$F_{\mathrm{q}}$ & discharge frequency \\
$G$ & groove width \\
$H$ & workpiece height \\
$k$ & thermal conductivity \\
$K$ & rising slope of the electrical current \\
$r$ & ratio of abnormal discharges to the total \\
& discharges \\
$S_{\mathrm{e}}$ & erosion rate of single discharge \\
$S_{\mathrm{v}}$ & servo voltage \\
$T_{\mathrm{off}}$ & discharge off time \\
$T_{\mathrm{on}}$ & discharge on time \\
$u_{0}$ & specific discharge energy \\
$V_{\mathrm{D}}$ & average working voltage \\
$W$ & discharge power \\
$W^{\prime}$ & discharge power actually provided by the \\
$W^{\prime \prime}$ & power supply \\
$\bar{W}$ & effective discharge power \\
$W_{\mathrm{s}}$ & power of single discharge \\
$\eta$ & discharge efficiency \\
$\rho$ & density \\
$\theta$ & average temperature generated on work- \\
$\bar{\theta}$ & piece surface \\
& average temperature at single discharge \\
& \\
\hline
\end{tabular}

are selected, and their machining characteristics under identical machining conditions are evaluated and compared. A quantitative relationship between machining characteristics and machining parameters is obtained through dimensional analysis of SDE. Different from previous studies that were limited to qualitative discussions, the derived relationship enables the behavior of WEDM to be understood more comprehensively.

\section{Theory of specific discharge energy}

In wire electrical discharge machining, a metal wire is used as the electrode and de-ionized solvent as the machining liquid. A specific electrical voltage is applied to both the electrode and workpiece. Once the gap between two electrodes is narrow enough, electrical discharge occurs. Material removal is accomplished through the thermal functions caused by the discharge, including evaporation and melting, and the function of force, including discharge impact pressure and explosive force, which expel the melted residue. Since the discharge process is a complex one, it is susceptible to the effect of a number of factors. However, from the perspective of discharge machining energy, each pulse during the discharge process is an output of energy. The energy distribution between the workpiece and wire electrode and the actual effective removal energy should be related to the distance between the wire electrode and workpiece, flushing pressure, conductivity of the machining liquid and discharge on time.

During wire electrical discharge machining, the discharge power is determined by the single discharge energy multiplied by discharge frequency. In reality, the discharge on time $\left(T_{\text {on }}\right)$ for the same machining operation must remain constant in order to obtain uniform groove width and stable machining. Fig. 1 illustrates the typical voltage and electrical current waves resulting from the pulse generator of the machine used in the experiment. The current produced by the pulse generator has an equilateral triangle shape. If the average working voltage is $V_{\mathrm{D}}$, then the single discharge energy is given by the following equation:

$\Delta E=\int_{\text {pulse_duration }} v(\tau) i(\tau) \mathrm{d} \tau=V_{\mathrm{D}} \times K \times T_{\text {on }}^{2}$

where $K$ denotes the rising slope of the electrical current and it is one of the design parameters of the discharge power source. Its unit is $\mathrm{A} / \mu \mathrm{s}$. Different machining conditions generate different discharge frequencies. Let the discharge frequency be $F_{\mathrm{q}}$, then the discharge power $(W)$ can be expressed as

$W=F_{\mathrm{q}} \times \Delta E=F_{\mathrm{q}} \times K \times V_{\mathrm{D}} \times T_{\mathrm{on}}^{2}$

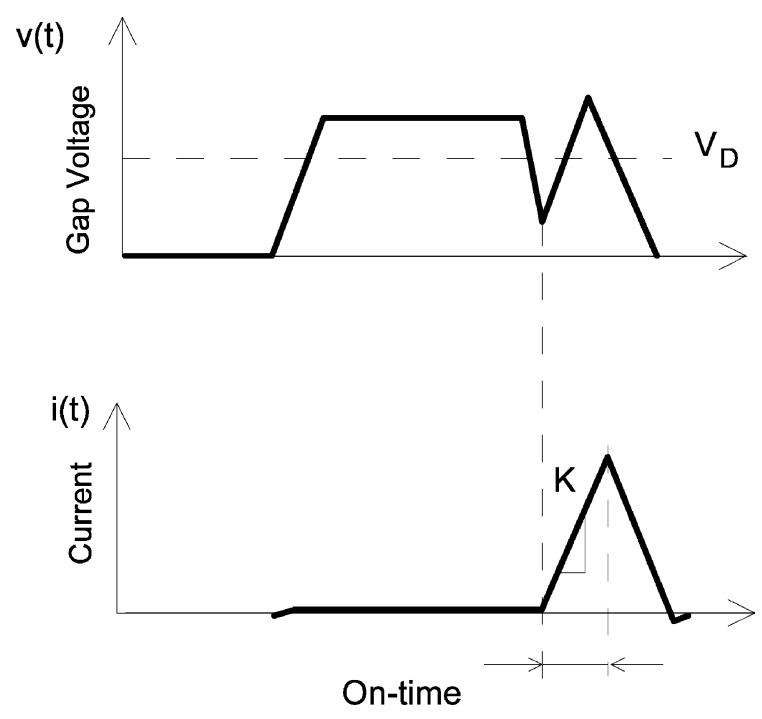

Fig. 1. Typical waveforms of voltage and current of a single discharge. 
For the machine used in the experiment, there are two sets of power parameters. Normal discharge time $T_{\text {on }}$ and off time $T_{\text {off }}$ are used when the discharge is normal. They are switched to $A_{\text {on }}$ and $A_{\text {off }}$, representing abnormal discharge time and off time, respectively, when an abnormal discharge is detected. Other machining parameters include servo voltage $S_{\mathrm{v}}$, wire speed $W_{\mathrm{s}}$ and flushing pressure. Not every discharge in the actual machining process is a normal discharge. Some are arc discharges while others are short pulses. Let the ratio of abnormal discharges in the total discharges, called abnormal ratio thereafter, be denoted by $r$. Arc discharge, based on the experimental data, usually accounts for half of the abnormal discharges, short discharge does not provide any discharge energy, hence the discharge power actually provided by the power supply denoted by $W^{\prime}$ is

$W^{\prime}=V_{\mathrm{D}} \times K \times F_{\mathrm{q}} \times\left(T_{\mathrm{on}}^{2} \times(1-r)+A_{\mathrm{on}}^{2} \times(r / 2)\right)$

One part of the energy supplied by the power source is used to remove workpiece material, the other is transmitted to the wire electrode, and the rest is distributed in the machining fluid. The effective energy that actually achieves workpiece removal accounts for part of the total energy, and it is related to the machining parameters, electrode and work materials $[8,9]$. Let the proportion of the total energy that is actually used for metal removal be defined as discharge efficiency and denoted by $\eta$, then the effective discharge power $W^{\prime \prime}$ is

$W^{\prime \prime}=W^{\prime} \times \eta$

The discharge efficiency is related to materials, machining parameters and condition of the machine. Defining the real energy needed to remove a unit volume of material during the machining process as the specific discharge energy (SDE), denoted by $u_{0}$, then SDE can be expressed as

$$
\begin{aligned}
u_{0} & =\frac{W^{\prime \prime}}{G \times H \times F} \\
& =\frac{V_{\mathrm{D}} \times K \times F_{\mathrm{q}} \times\left(T_{\mathrm{on}}^{2} \times(1-r)+A_{\mathrm{on}}^{2} \times(r / 2)\right) \times \eta}{G \times H \times F}
\end{aligned}
$$

where $G$ is the groove width, $H$ is the workpiece height, $F$ is the table feed rate.

SDE should be constant for a given material irrespective of machining conditions, and it can be considered as one of the properties of a material in wire-EDM. For a given work material, the discharge efficiency would be influenced by electrode material and machining parameters. By definition, it is readily understood that the larger the SDE the harder is material removal. The higher the discharge efficiency, the more is the energy distributed in workpiece during machining. Since SDE is a material property, it is expected that materials having equal SDE would result in identical machining characteristics (machining speed, surface roughness of the machined surface, groove width, discharge frequency, abnormal discharge ratio) if they are machined by the same machining conditions.

Eq. (5) can also be derived from dimensional analysis. Physically $u_{0}$ should be constant for a given material. All possible variables related to WEDM and their dimensions are listed in Table 1 . The quantities $\bar{\theta}$ and $\theta$ are the instantaneous temperature at single discharge instant, and the average temperature generated on workpiece surface, respectively. Quantities $k, \rho, c$ are the thermal conductivity, density and specific heat of work material. Similar to the traditional specific cutting energy in cutting [10], the average temperature on surface of workpiece should be influenced by $u_{0}$ and thermal properties of the material. Since material removal rate is related to machining speed and machining groove. Through dimension analysis a dimensionless equation is obtained as follows:

$\frac{\theta}{u_{0}}\left(\frac{k \times \rho \times c}{F \times G}\right)^{1 / 2}=C_{1}$

or

$u_{0} \sim \theta \times\left(\frac{k \times \rho \times c}{F \times G}\right)^{1 / 2}$

Considering the energy provided during wire electrical discharge machining, physical quantities related to energy are specific discharge energy, effective discharge power and temperature on the workpiece surface. Similarly, taking the workpiece height, where the energy or temperature is distributed on, into consideration,

Table 1

Dimension analysis of physical quantities

\begin{tabular}{lll}
\hline Physical quantity & Symbol & Dimension \\
\hline Specific discharge energy & $u_{0}$ & $F L^{-2}$ \\
Table feed rate & $F$ & $L T^{-1}$ \\
Average temperature generated & $\theta$ & $\theta$ \\
$\begin{array}{l}\text { on workpiece surface } \\
\text { Average temperature at single }\end{array}$ & $\bar{\theta}$ & $\theta$ \\
discharge instant & & \\
Groove width & $G$ & $L$ \\
Workpiece height & $H$ & $L$ \\
Thermal conductivity & $k$ & $F L T^{-1} L^{-1} \theta^{-1}$ \\
$\begin{array}{l}\text { Density } \\
\text { Specific heat }\end{array}$ & $\rho$ & $M L^{-3}$ \\
Effective discharge power & $c$ & $F L M^{-1} \theta^{-1}$ \\
Power of single discharge & $W^{\prime \prime}$ & $F L T^{-1}$ \\
Erosion diameter of single & $\bar{W}$ & $F L T^{-1}$ \\
discharge & $D$ & $L$ \\
Erosion rate of single discharge & $S_{\mathrm{e}}$ & $L T^{-1}$ \\
\hline
\end{tabular}

Temperature $(\theta)$, length $(L)$, time $(T)$, mass $(M)$, force $(F)$. 
another dimensionless equation is obtained as follows:

$\frac{1}{\theta}\left(\frac{W^{\prime} \times \eta \times u_{0}}{k \times \rho \times c \times H}\right)^{1 / 2}=C_{2}$

or

$\theta \sim\left(\frac{W^{\prime} \times \eta \times u_{0}}{k \times \rho \times c \times H}\right)^{1 / 2}$

Substituting Eq. (9) into Eq. (7) yields

$u_{0} \sim \frac{W^{\prime} \times \eta}{F \times G \times H}$

This is the same as the definition of specific discharge energy given previously in Eq. (5).

\section{Experiment and analysis of results}

The first goal of the experiment was to check if SDE is constant for a given material, and to verify if the machining characteristics are identical for the materials having equal value of SDE machined under the same machining conditions. The second purpose was to understand to what extent each machining parameter affects the discharge efficiency $\eta$. The experimental apparatus included a flushing type 5-axis $\mathrm{CNC}$ wire electrical discharge machine manufactured by ChingHong Inc., Taiwan. The main unit is equipped with an iso-energy discharge wave power supply system that generates triangular waves with equal slopes and a peak current slope of $450 \mathrm{~A} / \mu \mathrm{s}$. The average working voltage was $80 \mathrm{~V}$. Machining parameters can be adjusted from the control panel. The wire electrode was 6-4 brass wire $60 \%(\mathrm{Cu}), 40 \%(\mathrm{Zn})$ with a diameter of $0.25 \mathrm{~mm}$. Its tensile strength was $95-105 \mathrm{kgf} / \mathrm{mm}^{2}$ and the melting point was $930{ }^{\circ} \mathrm{C}$. Experiments were conducted under G95 mode. In others words, the servo voltage control was set in machining.

\subsection{Specific discharge energy and its relationship with machining characteristics}

According to Table 2, two sets of machining conditions were selected at first, and four workpiece materials were used, namely, aluminium ( $\mathrm{Al}$ ) alloy, titanium
Table 2

Experimental machining parameters

\begin{tabular}{llllll}
\hline Set no & \multicolumn{3}{l}{ Machining parameter } & & \\
\cline { 2 - 6 } & $\begin{array}{l}\text { Discharge } \\
\text { on time } \\
(\mu \mathrm{s})\end{array}$ & $\begin{array}{l}\text { Discharge } \\
\text { off time } \\
(\mu \mathrm{s})\end{array}$ & $\begin{array}{l}\text { Arc on time } \\
(\mu \mathrm{s})\end{array}$ & $\begin{array}{l}\text { Arc off time } \\
(\mu \mathrm{s})\end{array}$ & $\begin{array}{l}\text { Servo } \\
\text { voltage } \\
(\mathrm{V})\end{array}$ \\
\hline 1 & 0.9 & 16 & 0.5 & 18 & 50 \\
2 & 0.7 & 16 & 0.5 & 18 & 45 \\
\hline
\end{tabular}

Other machining parameters: wire tension 1200 gf, wire speed $9 \mathrm{~m} /$ min, flushing pressure $20 \mathrm{~kg} / \mathrm{cm}^{2}$.

(Ti) alloy, stainless steel, a cold work tool steel, and a hot work tool steel. Based on Eq. (5), the SDE of different materials was calculated individually by assuming the discharge efficiency $\eta$ was 1.0. The SDE of various materials under two sets of machining conditions are listed in Table 3 . The values in brackets are values relative to the 6061 aluminium alloy. From Table 3, it is noted that different values of SDE arise for each material under the two different machining conditions rather than just one value as postulated. The reason is that the discharge efficiency is different for the different machining conditions, but since it is unknown beforehand it was taken to be one in both cases. It is also noted that the relative relationship of SDE between different materials (i.e. the values given in the brackets) remains unchanged as machining conditions were the same for each one. This result also indirectly supports the postulation that the SDE for a given material should be constant.

The next experiment is to verify that the materials having the same SDE have identical machining characteristics if they were machined under the same machining conditions. Referring to Table 3, the two materials with similar SDE values, SKD11 and Inconel 718, were selected for this study. Their SDEs are 890 and $900 \mathrm{~J} / \mathrm{mm}^{3}$, respectively. They were machined under the machining conditions given in Table 4. Workpieces with a thickness of $15 \mathrm{~mm}$ were used in all experiments. The other machining conditions include the flushing pressure of $20 \mathrm{~kg} / \mathrm{cm}^{2}$, wire speed of $8 \mathrm{~m} / \mathrm{min}$ and wire tension of 900 gf. The resulting machining characteristics are summarized in Tables 5-7. They are: the abnormal ratio, defined as the proportion of abnormal discharges out of total discharges in a particular

Table 3

SDE of various materials $\left(\mathrm{J} / \mathrm{mm}^{3}\right)$

\begin{tabular}{lllllll}
\hline Set no & Al alloy 6061 & Super alloy Inconel 718 & Ti alloy Ti-6Al-4V & $\begin{array}{l}\text { Stainless steel } \\
\text { SUS 304 }\end{array}$ & $\begin{array}{l}\text { Cold work tool steel } \\
\text { SKD11 }\end{array}$ & $\begin{array}{l}\text { Hot work tool steel } \\
\text { SKD61 }\end{array}$ \\
\hline 1 & $275(1)$ & $900(3.27)$ & $690(2.51)$ & $840(3.05)$ & $890(3.24)$ & $980(3.56)$ \\
2 & $225(1)$ & $730(3.24)$ & $563(2.50)$ & $690(3.07)$ & $735(3.27)$ & $813(3.61)$ \\
\hline
\end{tabular}

( ) Relative to $\mathrm{Al} 6061$ values. 
Table 4

Experimental machining parameters

\begin{tabular}{llllll}
\hline Set no & \multicolumn{4}{l}{ Machining parameter } \\
\cline { 2 - 6 } & $\begin{array}{l}\text { Discharge } \\
\text { on time }(\mu \mathrm{s})\end{array}$ & $\begin{array}{l}\text { Discharge } \\
\text { off time }(\mu \mathrm{s})\end{array}$ & $\begin{array}{l}\text { Arc on } \\
\text { time }(\mu \mathrm{s})\end{array}$ & $\begin{array}{l}\text { Arc off } \\
\text { time }(\mu \mathrm{s})\end{array}$ & $\begin{array}{l}\text { Servo } \\
\text { voltage }(\mathrm{V})\end{array}$ \\
\hline 1 & 0.9 & 16 & 0.5 & 18 & 50 \\
2 & 0.9 & 16 & 0.5 & 18 & 40 \\
3 & 0.7 & 16 & 0.5 & 18 & 40
\end{tabular}

Other machining parameter: wire tension 1200 gf, wire speed $9 \mathrm{~m} /$ min, flushing pressure $20 \mathrm{~kg} / \mathrm{cm}^{2}$.

time interval, machining speed, discharge frequency, groove width and roughness of the machined surface. As it can be seen from the tables, the values of each of these machining characteristics are almost the same. This indicates that materials with similar SDE values exhibit very similar machining characteristics as long as they are machined under the same machining conditions. By this finding, it is concluded that, based on the evidence obtained so far, SDE postulated in paper can fully reflect the properties of a material in wireEDM. One of the real applications of this finding is to include SDE as one of a machining parameter in constructing the neural network model between machining parameters and machining characteristics. Prediction of the machining characteristics of different materials having different SDE can then be accomplished through the network. And once the neural network model is established, it can be applied for process planning. This work is beyond the scope of this paper and is not reported here.

\subsection{Effect of machining parameters on discharge efficiency}

A different discharge efficiency arises for different machining conditions. After considering realistic machining conditions, all identified variables that may affect discharge efficiency were selected as the control factors in the experiment undertaken to investigate this fact. They are workpiece thickness, discharge on time, discharge off time, arc on time, arc off time, wire speed, flushing pressure and servo voltage. Because of the large number of control factors, the L18 mixed orthogonal table of the Taguchi quality design method [11] was adopted. The level settings for all factors in the experiment are listed in Table 8. The machining characteristics under study were: groove width, machining speed, discharge frequency, abnormal ratio, roughness of the machined surface, and discharge efficiency. It should be noted that the discharge efficiency for a machining condition is unknown in practice. Hence, for analysis purpose, the relative value with respect to a standard value was computed. In our case, the machining condition of $T_{\text {on }}=0.9 \mu \mathrm{s}, S_{\mathrm{v}}=50 \mathrm{~V}$ was taken as the standard. By considering the SDE for a material is constant, and the discharge efficiency equals 1 under the standard machining condition, the relative value of discharge efficiency under different machining condition can be computed. After conducting the experiments, the signal to noise $(S / N)$ ratios were computed, and the analysis of variable was employed to find the significant factors affecting each machining characteristics. The results are given in Table 9. In

Table 5

Machining characteristics of SKD11 and Inconel 718 machined under the condition set no. 1

\begin{tabular}{|c|c|c|c|c|c|c|}
\hline \multicolumn{2}{|c|}{ Machining characteristic } & \multirow{2}{*}{$\begin{array}{l}\text { Abnormal ratio } \\
38\end{array}$} & \multirow{2}{*}{$\begin{array}{l}\text { Machining speed } \\
6.9\end{array}$} & \multirow{2}{*}{$\begin{array}{l}\text { Spark frequency } \\
26.5\end{array}$} & \multirow{2}{*}{$\begin{array}{l}\text { Groove width } \\
354\end{array}$} & \multirow{2}{*}{$\begin{array}{l}\text { Surface roughness } \\
3.4\end{array}$} \\
\hline Material & SKD11 & & & & & \\
\hline & Inconel 718 & 37 & 6.8 & 26.5 & 349 & 3.2 \\
\hline
\end{tabular}

Unit: abnormal ratio $(\%)$, machining speed $(\mathrm{mm} / \mathrm{min})$, spark frequency $(\mathrm{kHz})$, groove width $(\mu \mathrm{m})$, surface roughness $(\mu \mathrm{m})$.

Table 6

Machining characteristics of SKD11 and Inconel 718 machined under the condition set no. 2

\begin{tabular}{|c|c|c|c|c|c|c|}
\hline \multicolumn{2}{|c|}{ Machining characteristic } & \multirow{2}{*}{$\begin{array}{l}\text { Abnormal ratio } \\
45\end{array}$} & \multirow{2}{*}{$\begin{array}{l}\text { Machining speed } \\
8.2\end{array}$} & \multirow{2}{*}{$\begin{array}{l}\text { Spark frequency } \\
32.0\end{array}$} & \multirow{2}{*}{$\begin{array}{l}\text { Groove width } \\
349\end{array}$} & \multirow{2}{*}{$\begin{array}{l}\text { Surface roughness } \\
3.7\end{array}$} \\
\hline Material & SKD11 & & & & & \\
\hline & Inconel 718 & 45 & 8.0 & 31.5 & 346 & 3.6 \\
\hline
\end{tabular}

Table 7

Machining characteristics of SKD11 and Inconel 718 machined under the condition set no. 3

\begin{tabular}{lllllll}
\hline Machining characteristic & Abnormal ratio & Machining speed & Spark frequency & Groove width & Surface roughness \\
\hline Material & SKD11 & 44 & 6.3 & 32.0 & 340 & 3.2 \\
& Inconel 718 & 42 & 6.2 & 31.5 & 335 & 3.0 \\
\hline
\end{tabular}


Table 8

Experimental level settings

\begin{tabular}{lrrrl}
\hline Control factor & \multicolumn{2}{l}{ Level } & \multicolumn{1}{l}{ Unit } \\
\cline { 2 - 3 } & \multicolumn{1}{c}{2} & 3 & \\
\hline Thickness $H$ & 10 & 50 & & $\mathrm{~mm}$ \\
Discharge on time $T_{\text {on }}$ & 3 & 5 & 7 & $0.1 \mu \mathrm{s}(1-9 \mathrm{step})$ \\
Discharge off time $T_{\text {off }}$ & 20 & 35 & 50 & $1 \mu \mathrm{s}(8-50 \mathrm{step})$ \\
Arc on time $A_{\text {on }}$ & 2 & 3 & 4 & $0.1 \mu \mathrm{s}(1-5 \mathrm{step})$ \\
Arc off time $A_{\text {off }}$ & 20 & 35 & 50 & $1 \mu \mathrm{s}(9-50 \mathrm{step})$ \\
Servo voltage $S_{\mathrm{v}}$ & 40 & 55 & 70 & $\mathrm{~V}(35-70 \mathrm{~V})$ \\
Wire speed $W_{\mathrm{s}}$ & 5 & 7 & 10 & $1-16 \mathrm{~m} / \mathrm{min}(0-15 \mathrm{step})$ \\
Flushing pressure $F_{\mathrm{w}}$ & 3 & 5 & 7 & $0-20 \mathrm{~kg} / \mathrm{cm}^{2}(0-7 \mathrm{step})$ \\
\hline
\end{tabular}

Table 9

Influences of the machining parameters on machining characteristics

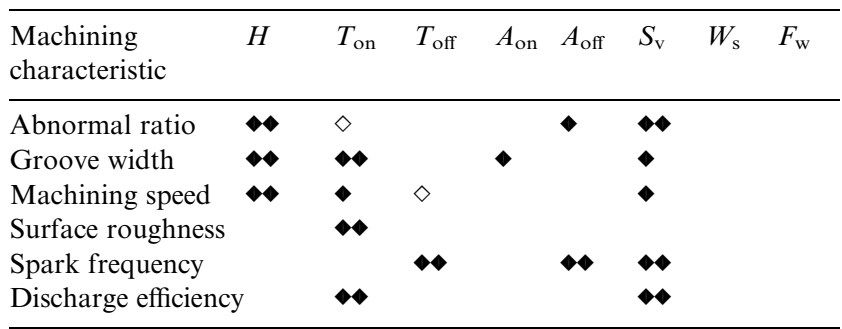

$\diamond$, most significant factor; $\bullet$, significant factor; $\diamond$, less significant factor.

addition, the trends in the variations of machining characteristics with respect to each significant machining parameter plotted and were shown in Table 10.

Referring to Table 9, it is found that the discharge on time and servo voltage are the two most significant factors affecting the discharge efficiency $\eta$. The larger the discharge on time, the lower the discharge efficiency. Since the amount of input energy depends strongly on the discharge on time, this implies that given a high energy during the machining process, the percentage of effective energy that actually reaches the workpiece and removes the material declines significantly. A similar conclusion had also been reached previously by others [12-15]. For the effect of servo voltage, a greater servo voltage results in lower discharge efficiency. The reason is that servo voltage reflects the distance between the wire electrode and workpiece. The shorter is this distance, the more likely a higher percentage of effective energy will achieve material removal. In other words, discharge efficiency is negatively correlated with the distance between the wire electrode and the workpiece.

\section{Some applications of specific discharge energy}

The SDE can be brought to several applications. Machining characteristics in WEDM studied previously such as groove width and surface roughness have been limited to qualitative discussions of the experimental results. In the following, a quantitative relationship between machining characteristics and machining parameters is obtained through SDE. The derived relationship enables an understanding of the behavior of WEDM more comprehensively, and can be applied for the future development of servo control strategy.

\subsection{Estimation of machining groove width}

A too large variation of the groove width will influence the dimensional accuracy of machined workpiece. Therefore, machining parameters must be decided carefully. From Table 9, it is concluded that workpiece height, discharge on time, arc on time and servo voltage have a significant effect on the machined groove width. Among these, discharge on time and workpiece height are the most significant factors, while arc on time and servo voltage have a secondary effect. Table 10 shows that a greater discharge on time and arc on time, and increase of workpiece height leads to a wider groove. In addition, machined groove width is positively correlated to average gap voltage, and it is negatively related to machining speed. If the gap voltage is reduced and the machining speed is increased, the machined groove width will be reduced. If Eq. (5) is rewritten as:

$$
G=\frac{V_{\mathrm{D}} \times K \times F_{\mathrm{q}} \times\left(T_{\mathrm{on}}^{2} \times(1-r)+A_{\mathrm{on}}^{2} \times(r / 2)\right) \times \eta}{u_{0} \times H \times F},
$$

then a quantitative relationship for machined groove width is obtained. The workpiece height, discharge efficiency and material (that is SDE) are fixed during

Table 10

Variation of machining characteristics varied with respect to significant machining parameters

\begin{tabular}{lllllll}
\hline & Abnormal ratio & Groove width & Machining speed & Surface roughness & Spark frequency & Discharge efficiency \\
\hline$H$ & $\nearrow$ & $\nearrow$ & $\nearrow$ & $\nearrow$ & $\searrow$ \\
$T_{\text {on }}$ & $\nearrow$ & $\nearrow$ & $\nearrow$ & $\searrow$ & \\
$T_{\text {off }}$ & & $\nearrow$ & & & \\
$A_{\text {on }}$ & $\searrow$ & $\nearrow$ & $\searrow$ & $\searrow$ & $\searrow$ \\
$A_{\text {off }}$ & $\searrow$ & $S_{\mathrm{v}}$ & $\searrow$ & $\searrow$ & $\searrow$ \\
\hline
\end{tabular}

$\nearrow$, machining characteristics increasing; \, machining characteristics decreasing. 
machining, while other physical quantities can be measured on line, hence the variation of machining groove width can be estimated on line.

When estimating the variation of machined groove width on line is wanted, a mathematical model relating discharge efficiency $\eta$ and discharge on time and servo voltage is needed, and the simplest approach is to establish this relationship by regression analysis. By postulating the quadratic form functional relationship, the model can be expressed as:

$\eta=X \beta+\varepsilon$

where $X$ is matrix of $\left[\begin{array}{llllll}X_{1}^{2} & X_{2}^{2} & X_{1} X_{2} & X_{1} & X_{2} & 1\end{array}\right]$, where $X_{1}$ and $X_{2}$ are related to significant factors. $\beta=$ $\left(X^{T} X\right)^{-1} X^{T} Y, \quad X_{1}=\log \left(T_{\text {on }}\right) / \max \left(\log \left(T_{\text {on }}\right)\right), \quad X_{2}=$ $\log \left(V_{\mathrm{g}}\right) / \max \left(\log \left(V_{\mathrm{g}}\right)\right)$, and $3 \leq T_{\mathrm{on}} \leq 9,30 \leq V_{\mathrm{g}} \leq 80$. Hence $0.5 \leq X_{1} \leq 1,0.776 \leq X_{2} \leq 1$.

After curve fitting of experimental data yields

$$
\begin{aligned}
\eta= & 1.5682 X_{1}^{2}+3.18546 X_{2}^{2}-2.7395 X_{1} X_{2} \\
& -2.0132 X_{1}-4.3356 X_{2}+5.2435
\end{aligned}
$$

The correlation coefficient $R$ that stands for the goodness of fit is found to be 0.9954 . This high correlation coefficient value of almost 1 indicates that the above mathematical expression relating discharge efficiency, discharge on time and servo voltage, established through regression is highly representative and acceptable.

\subsection{Analysis of a single discharge}

The surface of a WEDM'd workpiece is formed by the pits resulting from many discharges. This surface is not smooth and is usually quantified by surface roughness. The surface roughness is mainly determined by the peak current value; the larger the peak current value, the larger the surface roughness.

From the perspective of a single discharge during the machining process, let the erosion diameter of each single discharge be $D$, the rate of erosion toward the inside of workpiece be $S_{\mathrm{e}}$, and the average temperature at the single discharge instant be denoted by $\bar{\theta}$. The workpiece surface roughness is positively correlated with $S_{\mathrm{e}}$. Referring to Eq. (6), the following equation can be derived by analogy

$$
\frac{\bar{\theta}}{u_{0}} \times\left(\frac{k \times \rho \times c}{D \times S_{\mathrm{e}}}\right)^{1 / 2}=C_{3}
$$

Rearranging the above equation, the single discharge erosion rate can be written as

$$
S_{\mathrm{e}} \sim\left(\frac{k \times \rho \times c}{D}\right) \times\left(\frac{\bar{\theta}}{u_{0}}\right)^{2}
$$

If $\bar{W}$ denotes the power of a single discharge, it can be expressed as the energy provided of a single discharge divided by the total pulse time which is twice that of discharge time. That is:

$\bar{W}=\frac{K \times V_{\mathrm{D}} \times T_{\text {on }}}{2}$

For a single normal discharge, the physical quantities related to average temperature at discharge instant are power of a single discharge, specific discharge energy, thermal properties of material, discharge efficiency, and the erosion diameter of a single discharge. Similar to Eq. (8), a dimensionless relationship is obtained by analogy.

$\frac{1}{\bar{\theta}} \times\left(\frac{\bar{W} \times u_{0} \times \eta}{k \times \rho \times c \times D}\right)^{1 / 2}=C_{4}$

Hence

$\bar{\theta} \sim\left(\frac{\bar{W} \times u_{0} \times \eta}{k \times \rho \times c \times D}\right)^{1 / 2}$

Substituting Eq. (18) into Eq. (15) yields

$S_{\mathrm{e}} \sim\left(\frac{\bar{W} \times \eta}{u_{0} \times D^{2}}\right)$

Then the rate of material removal (volume/time) is

$S_{\mathrm{e}} \times D^{2} \sim\left(\frac{\bar{W} \times \eta}{u_{0}}\right)$

The efficiency of material removal defining as the volume of material removal per unit energy input (volume/energy) is

$\frac{S_{\mathrm{e}} \times D^{2}}{\bar{W}} \sim\left(\frac{\eta}{u_{0}}\right)$

It is well known from experience that an increase in discharge on time results in a rise of machining speed or material removal. However, it has been discussed in Section 3.2 that the greater the discharge on time, the smaller the discharge efficiency. Hence, with the aid of Eq. (20), it can be concluded that the amount of the decrease of discharge efficiency is less than the increase of $\bar{W}$ due to the increase of the discharge on time. It should also be noted that while the rate of material removal is increased, the efficiency of material removal will decrease when discharge on time is increased in rough machining as depicted by Eqs. (20) and (21). Surface roughness is positively correlated with the single discharge erosion rate $S_{\mathrm{e}}$. Again, It is clear from Eq. (19) that roughness of the machined surface is increased with the rate of energy provided by single discharge and discharge efficiency. But it inversely varies with SDE and the erosion diameter of a single discharge. Under the same machining conditions, the surface roughness will improve when there is a greater SDE, and vice versa. 


\section{Conclusion}

1. A new concept of specific discharge energy (SDE) is presented in the paper. It is found that this quantity is a material property in WEDM. The relative relationship of SDE for different materials is fixed as long as these materials are machined under the same machining conditions. Materials having similar value of SDE display very similar machining characteristics if they are machined under the same machining condition.

2. By means of dimensional analysis of SDE, a quantitative relationship between the machining parameters and gap width in WEDM is obtained. This relationship will be extremely helpful to the development of new servo control strategy.

3. Under steady machining process, the smaller discharge gap results in higher discharge efficiency. The shorter the normal discharge on time, the higher the discharge efficiency.

4. The material removal is increased but the efficiency of material removal (i.e. volume of material removal per unit energy input) is decreased with the increase of discharge on time. Under the same machining conditions, the surface roughness will become better when there is a greater SDE, and vice versa.

5. Finally, using the characteristics of SDE, determination of parameter settings for different materials can be greatly simplified, and this work is under way.

\section{References}

[1] J. Prohaszka, A.G. Mamalis, N.M. Vaxevanidis, The effect of electrode material on machinability in wire electro-discharge machining, Journal of Materials Processing Technology 69 (1997) 233-237.

[2] P.M. Lonardo, A.A. Bruzzone, Effect of flushing and electrode material on die sinking EDM, Annals of the CIRP 48 (1) (1999) $123-126$.

[3] G.N. Levy, F. Maggi, WED machinability comparison of different steel grades, Annals of the CIRP 39 (1) (1990) 183-185.

[4] S.M. Pandit, K.P. Rajurkar, A stochastic approach to thermal modelling applied to electro-discharge machining, Transactions of the ASME, Journal of Heat Transfer 105 (1983) 555-558

[5] G. Spur, J. Schönbeck, Anode erosion in wire-EDM - a theoretical model, Annals of the CIRP 42 (1) (1993) 253-256.

[6] R. Snoeys, F. Van Dijck, Investigation of EDM operations by means of thermo-mathematical models, Annals of the CIRP 20 (1) (1971) $35-36$

[7] M. Jennes, R. Snoeys, Comparsion of various approach to model the thermal load on the EDM-wire electrodes, Annals of the CIRP 33 (1) (1984) 93-98.

[8] W. König, Material removal and energy distribution in electrical discharge machining, Annals of the CIRP 24 (1) (1975) 95-100.

[9] M. Motoki, K. Hashiquchi, Energy distribution at the gap in electric discharge machining, Annals of the CIRP 14 (1967) 485-488.

[10] M.C. Shaw, Metal Cutting Principles, Clarendon Press, Oxford, 1984.

[11] P.J. Ross, Taguchi Techniques for Quality Engineering, McGraw-Hill Book Company, 1989.

[12] Y.F. Luo, An energy-distribution strategy in fast-cutting wire EDM, Journal of Materials Processing Technology 55 (1995) 380-390.

[13] D.D. DiBitonto, P.T. Eubank, M.R. Patel, M.A. Barrufet, Theoretical models of the electrical discharge machining process. I. A simple cathode erosion model, Journal of Applied Physics 66 (1989) 4095-4103.

[14] D.D. DiBitonto, P.T. Eubank, M.R. Patel, M.A. Barrufet, Theoretical models of the electrical discharge machining process. II. The anode erosion model, Journal of Applied Physics 66 (1989) 4104-4111.

[15] P.T. Eubank, M.R. Patel, M.A. Barrufet, B. Bozkurt, Theoretical models of the electrical discharge machining process. III. The variable mass, cylindrical plasma model, Journal of Applied Physics 73 (1993) 7900-7905. 